\title{
DIPLOMACIA FINANCIERA \\ E INTERMEDIACIÓN \\ EN LA RENEGOCIACIÓN DE LA DEUDA \\ EXTERNA MEXICANA, 1836-1842
}

\author{
Gabriel Martínez Carmona \\ El Colegio de Michoacán
}

INTRODUCCIÓN

F s sabido que México contrató un par de préstamos con Cdos casas comerciales británicas (1824 y 1825), las cuales se encargaron de colocar los bonos mexicanos en el mercado de Londres. El país utilizó la parte de los recursos que llegaron al país para cubrir gasto corriente y comprar armamento, necesario para consolidar la defensa frente a las amenazas externas, particularmente de España. Sin embargo, la joven república no pudo enviar el dividendo correspondiente a finales de $1827 \mathrm{y}$ cayó en moratoria en 1828, con lo que el mercado de crédito internacional quedó cerrado para el país por cerca de medio siglo. Gracias a diversas investigaciones, se sabe de la condiciones onerosas en que se negociaron los préstamos y de lo pesada que fue la carga del servicio de la deuda para el erario nacional, en comparación con las negociaciones de otros países de América

Fecha de recepción: 23 de mayo de 2020

Fecha de aceptación: 14 de julio de 2020

HMex, LXXI: 3, 2022 
Latina. ${ }^{1}$ Otro tanto se ha dicho sobre el papel de las principales merchant banker houses en el primer ciclo de endeudamiento de los nuevos países latinoamericanos, así como de la relación entre la deuda y la guerra en los procesos de renegociación de deuda soberana. ${ }^{2}$

Estas investigaciones han abordado, aunque de manera indirecta, el tema de la diplomacia financiera, puesto que sus intereses se han enfocado en la parte económica de la deuda exterior y no en la serie de negociaciones entre los representantes del gobierno mexicano y sus acreedores. ${ }^{3}$ Por diplomacia financiera me refiero a una parte de la diplomacia económica que se concibe como el conjunto de acciones proyectadas por los tomadores de decisiones a nivel nacional para atraer y suministrar recursos y herramientas financieros del ámbito internacional. Ésta se distingue de otras formas de diplomacia porque en ella los ministros del exterior no necesariamente encabezan el proceso de toma de decisiones, pues éste involucra intereses y maniobras de una pluralidad de agencias que actúan dentro del gobierno. En la diplomacia financiera además existe un vínculo significativo entre actores estatales y privados, lo que implica cierta difuminación al momento de distinguir la cadena de mando en la toma de decisiones. ${ }^{4}$ Este tipo de diplomacia, de acuerdo con un estudioso del tema, está fuertemente condicionada por las particularidades de cada coyuntura histórica, por lo que se

1 Bazant, Historia de la deuda; Rodríguez, El nacimiento; Rodríguez O., "Los primeros empréstitos"; Marichal, Historia de la denda; LieHr, "La deuda exterior"; Salvucci, Politics, Markets.

2 Dawson, The First; Flandreau y Flores, "Bonds and Brands"; Sicotte y VizCarra, "War and Foreign Debt".

${ }^{3}$ Dos excepciones son Aggarwal, Debt Games, quien analiza el fenómeno de la renegociación de la deuda desde la teoría de juegos, y Tomz, Reputation, quien propone una teoría de la reputación en la cooperación entre gobiernos soberanos e inversores extranjeros.

4 Okano-Heijmans, "Conceptualizing Economic"; Bayne y Woolcock, "What is Economic". 
encuentra en constante cambio. ${ }^{5}$ En consecuencia, no se puede hablar de "una diplomacia financiera", sino de una serie de episodios en que los actores involucrados establecieron procesos de negociación para obtener objetivos que respondían a coyunturas específicas.

La diplomacia financiera, por tanto, da una importancia sustancial a los actores involucrados. En este sentido, el papel que éstos desempeñan en el proceso de negociación resulta central en la obtención de los objetivos buscados por cada uno de ellos. El caso que aquí se analiza busca explicar cómo fue que la renegociación de la deuda externa de México entre 1836 y 1842 implicó un episodio de la diplomacia financiera en que el país se valió de la intermediación de un agente financiero, el cual actuó como intercesor entre el objetivo que el gobierno se proponía alcanzar y lo que los tenedores de bonos organizados en el comité de tenedores de bonos hispanoamericanos esperaban obtener.

Para explicar el proceso de la negociación entablada, se hará uso del modelo propuesto por Gould y Fernandez, ${ }^{6}$ para quienes cualquier intercambio mediado puede pensarse como una relación que involucra tres actores, dos de los cuales son partes actuales de la transacción y otro es el intermediario y cuyo objetivo es la obtención de poder. Los autores identificaron cinco tipos estructurales o tipos de relaciones de intermediación, en que el intermediario puede ser visto como "coordinador", "itinerante”, "portero", "representante” o "enlace”.

En éste, el gobierno mexicano se valió de un intermediario que cumplió el papel de agente financiero del país, ${ }^{7}$ la casa comercial

\footnotetext{
5 BAYNe, "Financial Diplomacy".

6 Gould y Fernandez, "Structures of Mediation".

7 De acuerdo con LieHr, "La deuda exterior”, p. 39: “La función del agente financiero consistía, sobre todo, en transferir, con ayuda del comisionista mexicano, remesas del gobierno a Londres, ganando una comisión por el cambio. Repartía, además, estas sumas por otra comisión pequeña de solo 1 a 1.5\%, a los tenedores de bonos mexicanos, como pago de intereses. Adicionalmente,
} 
F. de Lizardi y Compañía, establecida en Londres pero cuyos principales socios eran del estado de Veracruz, razón por la que el gobierno depositó en ella ciertas expectativas. ${ }^{8}$ La principal, y en la que me enfocaré, consistió en esperar que el agente financiero actuara en el proceso de intermediación como un "representante” en términos de afiliación, siguiendo la tipología de Gould y Fernández. ${ }^{9}$ Lo que propongo es que, por el contrario, la casa actuó de manera distinta a la esperada por el gobierno mexicano, lo que generó dificultades para la aprobación del nuevo arreglo y cuyo resultado final sería controversial, al punto de generar un escándalo en la bolsa de valores de Londres.

El artículo se divide en tres partes, ordenadas de manera cronológica y que responden a tres momentos de la negociación: el nombramiento del agente financiero en 1836, la propuesta de conversión presentada a los tenedores de bonos en 1837 y su aceptación en Londres y, por último, la negociación y ratificación del arreglo en México y posteriormente en Londres, entre 1837 y 1842. Por último, en las conclusiones se ofrece una posible explicación de las acciones de intermediación y sus resultados. En esta investigación se utiliza como fuente principal la correspondencia entre el agente financiero y el gobierno mexicano, resguardada en el Archivo de la Secretaría de Relaciones Exteriores, que no había sido utilizada por la historiografía hasta la fecha.

proporcionaba cuotas mensuales para el sustento de las representaciones diplomáticas del país en Londres y en el resto de Europa”.

8 Salvucci y Salvucci, “The Lizardi Brothers”.

9 "En negociaciones políticas, un miembro de un partido se puede aproximar a alguien de un partido rival mediante un intermediario que pertenece al grupo rival; alternativamente, él o ella puede intentarlo por medio de un miembro de su propio partido. Los intermediarios en estas dos situaciones desempeñan distintos papeles. En el primer caso, el intermediario actúa como un portero para su partido y puede decidir si da o no acceso a una parte de fuera. En el segundo caso, el intermediario actúa como representante de su partido e intenta establecer contacto con una parte de fuera". Gould y FERnANDEZ, "Structures of Mediation”, p. 92. 
Luego de la crisis de 1826 en la bolsa de Londres, algunas casas comerciales quebraron, entre ellas las dos prestamistas del gobierno mexicano: B. A. Goldschmidt y Cía., y Barclay, Herring, Richardson y Cía. ${ }^{10} \mathrm{~A}$ partir de entonces, gracias a las gestiones de Vicente Rocafuerte, entonces encargado de negocios de México en Londres, la casa Baring Brothers y Compañía absorbió los compromisos de Barclay y fue nombrado agente financiero del país en Londres, con lo que se encargaría de cubrir el dividendo de septiembre de 1826, así como los sueldos y gastos de los diplomáticos mexicanos en Europa. ${ }^{11}$ La merchant banking bouse era, junto con la casa Rothschild, las dos más importantes en el mercado londinense, lo que parecía traer buenos augurios para la reputación financiera mexicana en dicho mercado. ${ }^{12} \mathrm{Sin}$ embargo, el gobierno mexicano no logró cubrir el dividendo de finales de 1827 y cayó en moratoria. El año siguiente el presidente Guadalupe Victoria autorizó la capitalización de la deuda exterior, pero Baring advirtió que la mejor política que debía practicarse consistía en dejar de hacer promesas que no se cumplirían y modificar sustancialmente el sistema tributario del país. ${ }^{13}$ La capitalización no tuvo lugar y el país dejó de pagar su servicio.

10 El asunto ha sido estudiado por Dawson, The First; y Marichal, Historia de la deuda externa.

11 Alamán, Liquidación general, pp. 16-18; RodríGuez O., El nacimiento, pp. 170-172.

12 Austin, Baring Brothers; Ziegler, The Sixth; Ferguson, The House of Rothschild.

13 Alamán, Liquidación general, pp. 17-18; RodríGuez O., El nacimiento, p. 176; Salvucci, Politics, Markets, pp. 100-116. Sobre el sistema tributario mexicano existe un número considerable de trabajos: Hernández Jaimes, $L a$ formación; Aboites Aguilar y Jáuregui (coords.), Penuria in fin; SÁnchez SAntiró, Las alcabalas; Torres Medina, Centralismo y reorganización; 
El primer gobierno de Anastasio Bustamante (1830-1832) padeció de los mismos problemas deficitarios que sus antecesores, por lo que decidió regresar a la idea de capitalizar los intereses y encargó el asunto a su ministro de Relaciones Lucas Alamán. La capitalización de dividendos de 1831 consistió en la capitalización de los intereses que se debían desde 1827 y hasta abril de 1831, por un lado, así como la capitalización de la mitad de los intereses de los dos préstamos por vencer a partir de abril de 1831 y hasta el mismo mes de 1836. Esta capitalización tendría lugar a partir del 1o de abril de 1836, mediante la emisión de bonos, tomados a 62.5 y $75 \%$ de su valor nominal, para los de 5 y $6 \%$, respectivamente. ${ }^{14}$

Aunque se sabe poco de la negociación establecida entre 1830 y 1831, que implicó, por un lado, la colaboración de los ministros de Relaciones y de Hacienda, el ministro plenipotenciario de México en Londres y el agente financiero del país en la city, y por otro lado, a los tenedores de bonos, organizados en el primer comité de tenedores de bonos mexicanos, el resultado significó para México comprar tiempo para poder lidiar con el pago de dividendos atrasados y por venir, a cambio de aumentar alrededor de un tercio el monto total de la deuda externa, que pasó de 6000000 en 1830 a poco más de 9000000 de libras esterlinas en $1837 .{ }^{15}$ Esto dio un respiro a las finanzas públicas del gobierno de Bustamante; no obstante, el levantamiento de Santa Anna en 1832 le dio un giro a la política nacional. ${ }^{16}$

Sánchez Santiró, "El peso de la fiscalidad"; Serrano Ortega, Igualdad, uniformidad.

14 Colección de leyes, pp. 133-135 y 139-140; Alamán, Liquidación general, pp. 16-24; Salvucci, Politics, Markets, pp. 120-124; Costeloe, Denda externa, pp. 52-59.

15 Véase Salvucci, Politics, Markets, p. 191, tabla 3.4, elaborada con datos de Alamán.

16 VÁzquez, "Los pronunciamientos de 1832"; Costeloe, La primera república, pp. 327-349. 
La capitalización de los dividendos entre 1831 y 1836 calmaría el ánimo de los acreedores, pero el tiempo corría y a la llegada de la fecha límite, el sistema fiscal seguía sin recaudar lo suficiente para cubrir el déficit anual y la política interna entró en crisis en 1835 con diversas movilizaciones que pugnaban por un cambio en la organización política del país, argumentaban el fracaso del federalismo y proclamación el centralismo. La coyuntura fue hábilmente utilizada para justificar el levantamiento separatista en Texas, que llevaba tiempo fraguándose y culminó en la proclamación de su independencia de la República mexicana. ${ }^{17}$

$\mathrm{Al}$ tiempo de la serie de movilizaciones en la política nacional, Baring escribió en marzo de 1836 al encargado de negocios mexicano en Londres, Agustín de Iturbide, para solicitar instrucciones sobre lo que debía hacer, porque a partir del 1o de abril de 1836 se debían emitir nuevos bonos y la totalidad de ellos comenzaría a generar intereses. ${ }^{18}$ La respuesta de Iturbide fue que tampoco tenía noticia al respecto, por lo que Baring Brothers se negó a seguir cubriendo los presupuestos de las legaciones mexicanas en Europa, para poco después renunciar a la agencia financiera, ante la falta de interés del gobierno mexicano para dar instrucciones sobre cómo proceder.

De forma paralela a la incertidumbre en que se encontraba Baring Brothers entre marzo y junio de 1836, Agustín de Iturbide informó a México que había aceptado la "generosa oferta" que le hizo una casa de origen mexicano, F. de Lizardi y Compañía, para cubrir los presupuestos de las legaciones mexicanas en Europa, debido a la suspensión del envío de recursos por

17 El recuento más completo sobre la crisis del sistema federal es el de VázQuez y Ortega Serrano (coords.), Práctica y fracaso. Para el caso de Texas, el artículo de Soтo, “Texas y la federación”, pp. 575-594, en el libro antes referido.

18 AHGE-SRE, 3-11-4708, ff. 3-9. De Baring Brothers y Compañía a Agustín de Iturbide, Londres (1 mar. 1836), y Agustín de Iturbide a Baring Brothers y Compañía, Londres (4 mar. 1836). 
parte de Baring. El gobierno, por su parte, además de aprobar la decisión de Iturbide, agradeció a la casa "sobremanera la laudable conducta de ustedes en favor del decoro y buen nombre de su patria". ${ }^{19}$

Miguel, Francisco de Paula y Manuel Julián de Lizardi y Migoni eran tres hermanos de origen veracruzano, emparentados por el lado materno con Francisco de Borja Migoni, un acaudalado comerciante residente en Londres, quien fue el agente que negoció el primero de los dos préstamos que el gobierno mexicano contrató en aquella ciudad. A la muerte de su padre, su madre casó con José Javier Olazábal, quien se asentó en Nueva Orleans, al igual que otros españoles quienes tuvieron que migrar por las leyes de expulsión de 1827 y $1829 .{ }^{20}$ De acuerdo con Salvucci y Salvucci, una parte considerable de la riqueza inicial de los Lizardi, con la que comenzaron a invertir en Nueva Orleans, estuvo vinculada a la habilidad financiera del menor de los hermanos, Manuel Julián, quien encabezó el préstamo hecho al gobierno mexicano en1828, luego del cierre del mercado de crédito internacional, lo que dejó a la nueva república en manos de los agiotistas internos. ${ }^{21}$ Para la década de 1830 los hermanos tenían casas comerciales en Nueva Orleans, París y Londres con diferentes nombres: Lizardi Hermanos, M. de Lizardi y Compañía y F. de Lizardi y Compañía, respectivamente. Su capacidad para transferir montos considerables de capital desde México a otros sitios fue la clave del éxito de la empresa familiar.

No resulta sorprendente, por tanto, que los Lizardi se hicieran cargo de cubrir los presupuestos de las legaciones mexicanas en Europa, puesto que la reputación crediticia del país en el

19 AHGE-SRE, 3-11-4708, f. 10. De J. de la Fuente al oficial mayor encargado de la Secretaría de Relaciones, México (21 abr. 1836).

${ }^{20}$ La información sobre los hermanos Lizardi, previa al episodio aquí analizado proviene de Salvucci y Salvucci, "The Lizardi Brothers".

${ }^{21}$ Dublán y Lozano, Legislación mexicana, II, p. 46; Zavala, Razón de los préstamos; Tenenbaum, The Politics, pp. 30-33. 
mercado de Londres había sufrido un segundo golpe considerable -luego de la moratoria-, cuando Baring decidió dejar de cubrir los gastos de las legaciones de la joven república. Tres meses después de que Lizardi asumiera el encargo, Miguel Santa María, ministro plenipotenciario en Londres, escribía desde Madrid al ministro de Relaciones para convencer al gobierno mexicano de que los hermanos Lizardi se hicieran también cargo de la agencia financiera de México en Londres.

El ministro plenipotenciario informaba sobre la inconformidad de los tenedores de bonos por el incumplimiento en el pago de dividendos vencidos, así como en la mitad de los dividendos que comenzaron a generar intereses en abril de 1836, producto según éstos del "mal manejo de los caudales públicos, la falta de economía, las continuas oscilaciones y guerras civiles", entre ellas "la perfidia de los colonos de Texas". Luego de un breve resumen de la situación de la deuda, posterior a la capitalización de intereses, Santa María concluía que "es llegado el tiempo de concebir una gran idea y abrazar una resolución firme, capaz de salvar el crédito público, y levantar a la Nación del abatimiento que ha descendido en la opinión del mundo político". El negro panorama descrito por el ministro plenipotenciario al ministro de Relaciones no era más que el contexto necesario para plantear una solución en la que había trabajado previamente:

Habiendo tenido ocasión de tratar con intimidad en Londres al Sr. Dn. Francisco Lizardi y hermanos, reconocí en ellos gran fondo de probidad unido a grandes conocimientos mercantiles y en materia de crédito público. Esto y los sentimientos verdaderamente patrióticos que les noté, me indujo a entablar con aquellos S.S. varias conferencias sobre asuntos relativos a las mejoras y progresos, de que es susceptible nuestro país. Entre estos tratamos frecuentemente del de la deuda pública y de la posibilidad de darle un arreglo practicable que cediese en beneficio del crédito e intereses de la República. Les insté para que, haciendo uso de sus conocimientos sobre la materia 
e instruidos como lo están de los inmensos recursos que a favor del orden es capaz de proporcionar México bajo un gobierno estable, progresivo e ilustrado, meditasen un plan propio para conseguir aquel objeto. ${ }^{22}$

Los Lizardi le comunicaron a Santa María en diversas ocasiones, de manera confidencial, el plan trazado y le invitaron a hacer reflexiones y meditaciones oportunas para su realización y aprobación por parte del gobierno mexicano. A su vez, comunicaban que estaban dispuestos a embarcar un enviado especial para proponer y discutir el proyecto directamente con el ministro de Hacienda, a cambio de que se les otorgara la agencia financiera "plena y total de la República”.

En la comunicación de julio de 1836, Santa María instaba al gobierno a dar su aprobación lo antes posible, puesto que "es de considerarse en dicho plan las intenciones que envuelve respecto a la política exterior, y muy particularmente para poner un dique fuerte a las miras de ambición y codicia de la Nación vecina, puestas ya en práctica con la guerra provocada en Texas”, para concluir: "considero que una medida de esta naturaleza, o su equivalente, adoptada con celeridad y firmeza es la única salvación del crédito mexicano y el de sus intereses en las relaciones exteriores". ${ }^{23}$

Entre la aprobación para el nombramiento de agente financiero de la república a F. de Lizardi y Compañía y el envío del comisionado de la casa comercial a México, el año 1836 vio su fin, año en que la totalidad de los dividendos debía ser cubierta, sin que el país cumpliera con la reactivación de su pago. Casi una década

22 AHGE-SRE, 3-11-4708, ff. 18-26. De Miguel Santa María al ministro de Relaciones, Madrid (17 jul. 1836). Costeloe, Deuda externa, p. 62, basado en Miguel Santa María, cataloga a Lizardi como "una compañía de mexicanos patriotas".

${ }^{23}$ AHGE-SRE, 3-11-4708, ff. 18-26. De Miguel Santa María al ministro de Relaciones, Madrid (17 jul. 1836). 
después de que se involucraran en el jugoso negocio del crédito interno, los hermanos Lizardi se convirtieron no sólo en los agentes financieros de México en Londres, sino también en quienes pagaban al servicio diplomático de la joven república en Europa. A diferencia de Barclay o Baring Brothers, la casa Lizardi fue la primera agencia financiera de origen mexicano que representaba a su país, lo que pareció generar confianza en el mercado de Londres, que continuaba pensando que la república tenía recursos más que suficientes para cubrir su servicio de deuda, pero no buscaba los medios para encontrarlos $y$, por el contrario, se dedicaba a consumir los pocos que generaba en querellas internas.

\section{LAS NEGOCIACIONES EN LONDRES EN 1837}

En la recomendación de Santa María para nombrar a F. de Lizardi y Compañía como agente financiero aseguró que un asociado de la firma podría partir de inmediato a México para plantear el asunto directamente al ministro de Hacienda, lo que al parecer ocurrió entre julio de 1836 y febrero de 1837. Pedro de la Quintana, socio de la firma y excolaborador de Francisco de Borja Migoni en Londres, viajó a México con el proyecto. No he localizado registro de las reuniones, pero el resultado fueron las leyes de 4 y 12 de abril de 1837. La primera de ellas otorgaba facultades al gobierno para "hacer efectiva la colonización de los terrenos que sean y deban ser propiedad de la República, por medio de venta, enfiteusis o hipotecas, aplicando el importe [... a la amortización de la deuda nacional, contraída o que se contrajere $[\ldots]$ ". ${ }^{24}$ Como puede observarse, la ley anclaba el arreglo de la deuda pública, incluida la externa, a la colonización de terrenos nacionales, particularmente en el norte del país. Gracias a la autorización otorgada al Ejecutivo en la ley de 4 de

${ }^{24}$ Dublán y Lozano, Legislación mexicana, III, p. 352. 
abril, el 12 de abril se promulgó la segunda ley, que generaba los medios para lograr que la colonización se vinculara directamente al arreglo de la deuda externa. En ésta, se creaba un fondo consolidado al $5 \%$ anual, con el objeto de convertir la totalidad de la deuda, es decir, unificar los dos préstamos originarios, así como amortizarla.

La ley de 12 de abril es prueba suficiente del consenso que se había alcanzado entre el gobierno mexicano y el agente financiero, vía su negociador Quintana, sobre todo cuando se analizan los detalles incluidos en la misma. Lizardi se haría cargo de intercambiar los bonos viejos de $5 \%$ por bonos nuevos, que serían tomados al $100 \%$ de su valor, en tanto los bonos de $6 \%$ se tomarían a $112.5 \%$ y los cupones por intereses vencidos de ambos empréstitos se tomarían al 100\% de su valor. Sorprenden estos rangos en el tipo de cambio de los bonos, sobre todo si se toma en cuenta que los bonos diferidos de 5 y $6 \%$ se cotizaban en la bolsa de Londres en febrero de 1837 a 14 y $17 \%$, en tanto los activos se cotizaban a 17 y $25 \%$, respectivamente. No está de más señalar también que el porcentaje de cambio para los bonos aumentaría por sí mismo el monto total de la deuda externa. ${ }^{25}$

La única razón que parece justificar el hecho de tomar los viejos bonos en tan alto valor es que se buscaba compensar a los tenedores de bonos para que éstos aceptaran la conversión. Esto debido a que la ley de 12 de abril establecía que la mitad de sus importes se haría en nuevos bonos de $5 \%$ y la otra mitad en inscripciones de terrenos baldíos en los departamentos de Texas, Chihuahua, Nuevo México, Sonora y California, “a razón de cuatro acres por libra esterlina, y estas inscripciones, ganarán

25 Dublán y Lozano, Legislación mexicana, III, pp. 359-361. Para la cotización véase Costeloe, Deuda externa, pp. 50-51 y 60-61. Salvucci, Politics, Markets, p. 132, afirma que Lizardi relevó a Baring en la agencia financiera de México en 1835, pero como se mencionó previamente, el relevo no se dio sino hasta mediados de 1836. 
igualmente cinco por ciento de interés, hasta el día que se ponga a sus dueños en posesión de los terrenos, en cuyo acto se les hará el abono de estos intereses, aumentándoles proporcionalmente la propiedad que adquieran, siempre que se presenten a tomar posesión [...]”. Es decir que, además de convertir la mitad de la totalidad de los bonos en inscripciones de terrenos, se unificaría la tasa de interés para todos los bonos a $5 \%$, en tanto se otorgaba la posesión de los referidos terrenos. ${ }^{26}$

El artículo $3^{\circ}$ establecía que los dividendos se pagarían semestralmente, el primer día de abril y de octubre de cada año y comenzaría a partir de octubre de 1837. Para la amortización de la deuda no se establecía una fuente de recursos específica, de hecho, no se establecía de manera clara la fuente de recursos para el pago de dividendos. Lo que la ley afirmaba era que "entre tanto se arregla la remisión periódica de los fondos que se destinen al efecto", los tenedores de los cupones vencidos podrán exigir a los agentes financieros la entrega de certificados que podrían presentarse y ser admitidos como dinero efectivo, en pago de la sexta parte de derechos que se causen en las aduanas de Veracruz y Tampico. Todo parece indicar que los agentes financieros habían considerado como un hecho que México no podría cubrir los primeros pagos.

Los siguientes siete artículos de la ley de 12 de abril de 1837 establecían las bases para el cambio de bonos por tierras en el norte de México, lo que indica el claro interés por parte del gobierno de hacer efectivo el cambio de bonos por terrenos para su colonización. Parte del plan conversado entre Lizardi y Santa María, reportado por este último en julio de 1836 al gobierno mexicano, incluía también "las intenciones que envuelve respecto a la política exterior, y muy particularmente para poner un dique a las miras de ambición y codicia de la nación vecina, puestas

${ }^{26}$ Dublán y Lozano, Legislación mexicana, III, p. 360. El tipo de cambio de la época era de 5 pesos por libra esterlina. 
ya en práctica con la guerra provocada en Texas". ${ }^{27}$ Para lograr que la operación tuviera éxito, Lizardi solicitó al gobierno: 1) se le concedieran 10000000 de acres de tierras de las referidas en el artículo $7^{\circ}$ de la ley de 12 de abril, para con ellas interesar a algunas de las principales casas de comercio en Europa, lo que daría un impulso en escala a la conversión, y 2) se le concediera el 6\% del total del monto de la conversión en clase de comisión, para con esto "ceder algunas cantidades a las principales casas que debían influir en el logro de la operación [...] y erogar todos los desembolsos y gastos que ella demandaba". ${ }^{28}$ La totalidad de dicho monto sería puesto en efectivo por Lizardi, pero solicitaba la facultad para emitir bonos del fondo consolidado; de este modo la hacienda pública no tendría que hacer el desembolso en numerario.

Se pidió al Consejo de Gobierno que elaborara un dictamen sobre la solicitud de Lizardi y éste redujo de 6 a $2 \%$ la comisión en valor de tierras sobre la conversión que se concedería a la casa comercial, o que este $2 \%$ se pagaría en inscripciones de las tierras referidas o que podría pagarse en efectivo, pero entonces la comisión sería sólo de $1 \%$ y se pagaría cuando y como las circunstancias lo permitieran, asegurando este monto con las mismas tierras destinadas a la venta. Una vez de acuerdo con el dictamen del Consejo, el gobierno envió a Londres una copia del decreto de 12 de abril, así como la orden que reducía la comisión solicitada.

Tanto en junio como en julio, Lizardi informó al gobierno mexicano que veían problemas con la ley de 12 de abril, particularmente porque designaba como obligatoria la amortización de la mitad de la deuda a cambio de tierras. Sólo hasta hacerse pública la ley de 12 de abril en Londres, sería posible informar

27 AHGE-SRE, 3-11-4708, ff. 18-26. De Santa María al ministro de Relaciones Exteriores, Madrid (17 jul. 1836).

28 Alamán, Liquidación general, p. 25. 
de las medidas que se tomarían para lograr el éxito de la empresa, aunque ya había sido entregada una copia tanto al comité como a la bolsa de valores de Londres. Esto tuvo lugar el 24 de julio de 1837, cuando The Times publicó una copia de la ley, no sin sentenciar la falta de confianza en el gobierno mexicano. ${ }^{29} \mathrm{Se}$ llamó a reunión general a los tenedores de bonos mexicanos para el 9 de agosto, pero el panorama no era alentador. Un par de días antes de la reunión The Times publicó una nota al editor donde se manifestaba la oposición al arreglo, en principio por la natural desconfianza a la conversión de bonos por un gobierno con mala reputación, y también porque el cambio de bonos por terrenos era impracticable, en particular en Texas. ${ }^{30}$ Pese a ello, el mensaje tenía esperanza de que se podría llegar a un arreglo con un país que poseía recursos suficientes y que requería paz y orden, algo que el presidente Bustamante podría asegurar.

En la reunión general de tenedores de bonos se leyó una comunicación enviada por F. de Lizardi y Cía. al Comité de Tenedores de Bonos Hispanoamericanos, firmada el 4 de agosto, donde se presentaba esta propuesta:

México ha sido sometido a insurrecciones militares, y sus finanzas necesariamente han caído en desorden, mientras que la deuda aquí aumentaba anualmente, hasta ahora, cuando el principal y los intereses acumulados pueden tomarse en $\$ 48,000,000$, causando un interés anual de más de $\$ 2,500,000$, una cantidad completamente más allá de los recursos actuales de México para satisfacer. Los remedios que se presentaron para este desafortunado estado de cosas fueron primero ofrecer a los tenedores de bonos una porción

29 "Money-Market and City Intelligence", The Times (24 jul. 1837).

30 "Mexican Finance. To the Editor of The Times", The Times (7 ago. 1837). En palabras del autor: "Sobre el plan del gobierno mexicano de pagar sus deudas mediante concesiones de su territorio, solo quisiera señalar que el único potentado que hasta ahora les ha dado un ejemplo de tal arreglo es el cacique de Poyais". 
de la propiedad más valiosa y única disponible que posee la nación: verbigracia, sus tierras vacantes. ${ }^{31}$

Sobre el asunto controversial de la oferta de terrenos en la provincia de Texas, los agentes financieros de México buscaron apagar el fuego:

Aunque Texas ahora se resiste a la autoridad de México, ese asunto pronto llegará a su solución. Si prevalece el gobierno mexicano, habrá sin dificultades casi 100,000,000 de acres dentro de los límites de Texas (que sólo tiene una población de unas 30,000 almas), para asignar la cantidad necesaria a los tenedores de bonos británicos, y realmente pensamos que con mediana buena gestión, suponiendo que prevalezcan los tejanos, se reconocería el título de los tenedores de bonos. Pero dejando a un lado a Texas, hay un tramo de país entre el Río del Norte y Río Nueces, 100 millas de frente en el golfo mexicano, y que se extiende de regreso a las montañas, que contiene alrededor de 30,000,000 de acres, que todavía está vacante y podría ser apropiado para los tenedores de bonos. $\mathrm{Y}$ en el transcurso de unos pocos años deberá ser de gran valor, el alma y el clima se adaptan admirablemente a la producción de algodón, arroz, tabaco, lana y todo tipo de granos y ganado, y el clima es templado y el campo muy saludable. ${ }^{32}$

La propuesta del gobierno mexicano tenía un particular énfasis en el poblamiento de Texas y sus alrededores para ofrecer una solución a la rebelión texana. La comunicación enviada al Comité cerraba diciendo:

Este es el verdadero estado de la cuestión, y consideramos que el actual estado de cosas sin resolver entre México y Texas es una de las

31 “Mexican Bondholders", The Times (10 ago. 1837).

32 "Mexican Bondholders", The Times (10 ago. 1837). 
razones principales por las que el decreto debe tomarse tal como es sin demora, y otra razón es la gran pérdida de tiempo. Antes de que un nuevo proyecto de ley pudiera enmarcarse y enviarse a México, y allí debatirse y aprobarse, habrían transcurrido unos dos años, mientras que, de ser aceptado de inmediato, el tenedor de bonos tendría varios dividendos en su bolsillo.

Aunque la reunión fue álgida y dividida, en general hubo oposición a su aprobación, por lo que se llegó a la decisión de nombrar una comisión de cuatro personas que analizaría la propuesta en detalle y elaboraría una contrapropuesta.

Lizardi se encargó de informar al gobierno mexicano sobre la resolución de la reunión referida. La firma consideraba que la comisión especial de tenedores de bonos aceptaría la consolidación de la mitad de los bonos, pero que para la otra mitad se deberían expedir -en lugar de inscripciones de tierras- bonos diferidos que no generarían intereses. Lizardi sostenía que podía conseguir que se difiriese el cobro de intereses hasta 1866, fecha señalada para la amortización del fondo consolidado. Para que esto ocurriera, pidió al gobierno mexicano que otorgaran poderes suficientes para allanar las dificultades que fueran surgiendo, tanto para el agente financiero como para el ministro plenipotenciario. Advertía también al gobierno que se encargara de separar la sexta parte de los derechos de aduanas marítimas de Veracruz y Tampico, para que en cuanto se ratificaran los convenios se enviara el primer dividendo a los tenedores de bonos.

El 5 de septiembre de 1837 se reunieron nuevamente los tenedores de bonos para escuchar el dictamen de la comisión que analizó la propuesta del gobierno mexicano. La resolución de ésta fue aceptar la propuesta con modificaciones, las cuales habían sido señaladas por Lizardi en su carta previa. En la junta del 5, que fue reseñada por The Times, se destaca que hubo varias reuniones en que tanto Agustín de Iturbide, el encargado de negocios mexicano, como F. de Lizardi y Cía., no sólo tomaron 
parte sino que fueron consultados sobre si tenían autoridad suficiente para aceptar modificaciones a la propuesta..$^{33}$ Aunque Lizardi ya había solicitado los poderes, el dictamen presentado en la junta general de tenedores de bonos se dio a conocer bastante rápido, por lo que la coyuntura los orilló a aceptar las modificaciones elaboradas por la comisión, sin haber recibido facultades para ello.

El nuevo arreglo efectivamente estableció la emisión de bonos diferidos que no causarían intereses por diez años, con la opción de intercambiarlos por tierras. Para asegurar el pago de dividendos se comprometía la sexta parte del total de los derechos por aduanas marítimas de los puertos de Veracruz y Tampico. De no ser suficiente, se mantendría la hipoteca de la totalidad de las rentas del país, como establecían los bonos originales y, además, a petición de los tenedores de bonos, se estableció la hipoteca especial de 100000000 de acres de tierras baldías en los departamentos de Texas, Chihuahua, Nuevo México, Sonora y California, así como reservar particularmente 25000000 de acres de tierras del gobierno en los departamentos de más próxima comunicación con el Atlántico.

El tiempo que tomaba comunicarse entre ambos lados de aquel océano hacía muy complicada la toma de decisiones en momentos coyunturales, por lo que el escenario ideal sería entrar a negociaciones con poderes amplios. Sin embargo, cuando el gobierno mexicano envió a Londres "autorización competente para allanar todas las dificultades que puedan oponerse a la ejecución de la empresa [...] sujetando los arreglos que hicieren a la ratificación del Supremo Gobierno", ${ }^{34}$ el 4 de noviembre de 1837, tenía siete semanas que el agente financiero había llegado a un acuerdo. Mientras la carta con la autorización para actuar

\footnotetext{
33 “The Mexican Loan”, The Times (6 sep. 1837).

${ }^{34}$ AHGE-SRE, 3-11-4708, ff. 29-30. De Ignacio de Mora a José María Bocanegra, México (4 nov. 1837).
} 
cruzaba el Atlántico, se recibió en México la información del acuerdo establecido el 14 de septiembre y dado a conocer por los mismos Lizardi en la prensa londinense. ${ }^{35}$

A finales de noviembre el gobierno mexicano recibió copia del convenio e información de que ya se había puesto en práctica la conversión de bonos. El gobierno turnó el documento al Consejo de Gobierno para que éste emitiera su opinión al respecto. Se esperaba que el consejo ratificara el arreglo, puesto que el gobierno mexicano había enviado la autorización para la modificación del arreglo original. Sin embargo, éste emitió un dictamen contrario a la ratificación, en el que argumentaba que el convenio celebrado en septiembre "desnaturalizaría completamente el decreto de 12 de abril de 1837 "36 y desaprobaba la conducta tanto del encargado de negocios como del agente financiero.

La urgencia por lograr un arreglo que buscaba triangular los intereses mexicanos con la necesidad de "levantar su crédito" en el mercado de Londres y colocar un bloqueo efectivo a los intereses separatistas texanos y expansionistas estadounidenses dependía de la efectividad para negociar de su agente financiero quien, en colaboración con el representante diplomático, debía actuar en favor de los intereses nacionales. El parecer del Consejo de Gobierno era que Lizardi no había actuado en consecuencia. El gobierno mexicano entonces informó a F. de Lizardi y Cía., el 29 de diciembre de 1837, que "aunque consideraba útil y digno de consideración el convenio celebrado con los tenedores de bonos, no podía conferirle desde luego su aprobación", ${ }^{37}$ por lo que procedería a turnar el tema al Congreso para su estudio.

El año que da nombre a la conversión de la deuda externa terminó sin la ratificación del gobierno. El agente financiero de México en Londres, que debía actuar como “representante” del

35 “Conversion of Mexican Bonds", The Times (22 sep. 1837).

36 Alamán, Liquidación general, p. 32. No logré localizar el dictamen del Consejo de Gobierno, por lo que tomo la cita de Alamán.

37 Alamán, Liquidación general, p. 32. 
gobierno mexicano, al parecer había forzado la coyuntura a su favor. De acuerdo con el gobierno, Lizardi ejerció presión a Iturbide para que éste aprobara el convenio, aunque las fuentes disponibles permiten suponer que tanto Miguel Santa María como Agustín de Iturbide actuaron en coordinación con el agente financiero. Tocaba ahora al gobierno mexicano corregir la dirección de la diplomacia financiera.

\section{RATIFICACIÓN, “CELO PATRIÓTICO” Y SOBREEMISIÓN}

Una vez que el arreglo fue turnado al Congreso, la conversión de la deuda pasaría por un largo viacrucis de idas y vueltas entre los poderes de la Unión y las comunicaciones entre el gobierno y sus representantes en Londres. El bloqueo francés a los puertos mexicanos entre abril y diciembre de 1838 , provocado por reclamaciones de ciudadanos franceses establecidos en México y por una fase de expansionismo francés que bloquearía simultáneamente los puertos del Golfo de México y el puerto de Buenos Aires, no sólo provocó un conflicto internacional sino que representó un duro golpe a la tesorería del gobierno central, cuyas principales rentas provenían de los impuestos de las aduanas marítimas. ${ }^{38}$ Esto influiría directamente en el arreglo establecido entre Lizardi y los tenedores de bonos, puesto que no había ninguna fuente de recursos disponible para cubrir el servicio de la deuda. De forma irónica, el conflicto con Francia daría un respiro al gobierno mexicano para estudiar el convenio del año anterior, porque de nada servía enviar la ratificación a Londres si no iba acompañada del dividendo correspondiente.

El 10 de enero de 1838 el Ejecutivo envió una iniciativa al Congreso para considerar el convenio ya aprobado y puesto en práctica en Londres. La Cámara de Diputados aprobó la

38 VÁzquez, México, Gran Bretaña, pp. 138-145; Andrews, Entre la espada, pp. 249-263. 
iniciativa y la turnó al Senado para su estudio. Las comisiones de Relaciones y Hacienda emitieron un duro dictamen, hecho público a fines de marzo de 1838, en que rechazaron el arreglo con los mismos argumentos que el Consejo de Gobierno. ${ }^{39}$ Además de reprobar que incrementaba progresivamente el monto de la deuda, debido a la compensación de 10\% en la emisión de certificados de aduanas, las comisiones consideraban que era contrario al espíritu de la ley que le dio origen. ${ }^{40} \mathrm{El} \mathrm{dictamen}$ negaba autorización para ratificar el arreglo, sostenía que debía buscarse uno nuevo y que éste debía pasar por la venia del Congreso, único autorizado para "reconocer la deuda nacional y decretar el modo de amortizarla".

El dictamen del Senado fue recibido en Londres a finales de junio, casi tres meses después de su emisión. Poco antes de que esto ocurriera, Juan Nepomuceno Almonte, entonces encargado de negocios en Londres, escribió al ministro de Relaciones para urgirlo a enviar la ratificación, lo que ayudaría a ganar el apoyo británico en el conflicto con Francia. ${ }^{41}$ El 29 de junio de 1838 F. de Lizardi y Cía. se dirigió a Almonte para pedirle instrucciones sobre el modo en que debía operar, pues acababa de recibir una copia del dictamen del Senado que ordenaba suspender la conversión. En ésta el agente financiero presionaba al encargado de negocios para apurar las acciones. ${ }^{42}$ La respuesta de Almonte a Lizardi fue contraria a las instrucciones del gobierno. Luego de buscar convencer a Lizardi que, pese a la negativa del Senado, "el negocio de la conversión no puede darse por perdido en aquella

\footnotetext{
39 “Dictamen de las comisiones”, Diario del Gobierno de la República Mexicana (19 abr. 1838).

40 "Dictamen de las comisiones", Diario del Gobierno de la República Mexicana (19 abr. 1838).

41 AHGE-SRE, 3-11-4710, ff. 26-27. De J.N. Almonte al ministro de Relaciones Exteriores, Londres (14 jun. 1838).

${ }^{42}$ AHGE-SRE, 3-11-4710, f. 43. De F. de Lizardi y Cía. a J.N. Almonte, Londres (29 jun. 1838).
} 
cámara”, el diplomático mexicano decidió lavarse las manos al decir que no tenía facultades para decidir sobre el modo de proceder, pero que a su parecer el gobierno terminaría por darles la razón. ${ }^{43} \mathrm{Al}$ informar a México sobre su comunicación con Lizardi, Almonte argumentó:

Es preciso además no perder de vista que el negocio de que se trata es ventajoso a la nación, y que lo que hay que temer es que se arrepientan los tenedores de bonos al ver la resolución del Senado [...]. Permita Dios que yo me equivoque, pero tengo entendido que si no arreglamos el pago de la deuda extranjera de una manera satisfactoria, la independencia de México será cuestionable. ${ }^{44}$

La respuesta del entonces ministro de Hacienda, Eduardo Gorostiza, al encargado de negocios en Londres fue enviada a fines de agosto y se limitó a un llamado de atención de que "no existen en él ni en nadie facultades para suspender los efectos de una resolución del congreso". A su vez, Gorostiza avisaba que usaría toda su influencia en el Congreso para que tomaran en consideración el convenio de septiembre de 1837 o un nuevo proyecto de ley. ${ }^{45}$

Tomó un año entero que el Legislativo retomara el asunto. Luego de la aprobación en el Congreso, el tema se turnó al Senado en mayo ${ }^{46}$ y finalmente se logró la ratificación en México del convenio celebrado entre Lizardi y los tenedores de bonos el

43 AHGE-SRE, 3-11-4710, f. 44. De J.N. Almonte a F. de Lizardi y Cía., Londres (2 jul. 1838).

${ }^{44}$ AHGE-SRE, 3-11-4710, ff. 56-56v. De J.N. Almonte al ministro de Relaciones Exteriores, Londres (12 jul. 1838).

${ }^{45}$ AHGE-SRE, 3-11-4710, f. 74. De Gorostiza a J.N. Almonte, México (23 ago. 1838).

46 AHGE-SRE, 3-11-4711, ff. 43-43v. Del ministro de Relaciones Exteriores a Máximo Garro, México (1o mayo 1839). 
1 o de junio de 1839 , con modificaciones para su operatividad. ${ }^{47}$ Se pidió, tanto a Lizardi como al encargado de negocios que se emitiera el menor número posible de certificados de aduanas, con el fin de que los montos recibidos en las de Veracruz y Tampico fueran suficientes para completar los dividendos. Lizardi por su parte comunicó a México que, hasta julio de 1839, no había emitido certificado alguno, debido a que la ratificación por el gobierno mexicano estaba en suspenso. ${ }^{48}$

Tanto Lizardi como Tomás Murphy, recién nombrado encargado de negocios en Londres, aseguraron en sus respectivas comunicaciones de agosto de 1839 que, pese a la aprobación del convenio de 1837 en México, en Londres había mucho que hacer para levantar la reputación crediticia del país, tarea de la que ambos se encargarían, pero la llave del éxito de su empresa residía en el cumplimiento de los términos establecidos. ${ }^{49}$ Debido a que el gobierno dio la orden a las aduanas de Veracruz y Tampico para separar la sexta parte de los derechos generados en octubre de 1839, ésta comenzaba a tener efecto el 1ㅇ de noviembre, lo que provocó que el dividendo de octubre de ese año no fuera separado y Lizardi tuviera que emitir los primeros certificados de aduanas, que para fin de año acumulaban 95310 libras, cuando de acuerdo con el convenio de 1837 debían cubrirse semestralmente 115592 libras por concepto de dividendos, por

47 Dublán y Lozano, Legislación mexicana, III, pp. 624-631. Uno de los ausentes fue, como señaló Alamán, una junta directiva de colonización, cuya formación se anunció en la ley, pero que hasta 1842 seguía sin establecerse. AlAmán, Liquidación general, pp. 52-53.

${ }^{48}$ AHGE-SRE, 3-11-4711, ff. 87-88. De F. de Lizardi y Cía. al ministro de Relaciones Exteriores, Londres (13 ago. 1839).

49 AHGE-SRE, 3-11-4711, ff. 87-88. De F. de Lizardi y Cía. al secretario de Relaciones Exteriores, Londres (13 ago. 1839). AHGE-SRE, 3-11-4711, ff. $90-$ 91v. De Thomas Murphy al ministro de Relaciones Exteriores (13 ago. 1839). En las comunicaciones se escribía Thomas y Tomás de manera indistinta, incluso por el personaje referido, por lo que se usará de acuerdo con cómo se encuentre en el original. 
lo que para octubre de 1839 estos acumulaban 462368 libras o 2311840 pesos. $^{50}$

El cumplimiento en el envío de recursos era vital para levantar y mantener una buena reputación en los mercados de crédito internacional. En eso Lizardi y Murphy decían verdades obvias, pero era precisamente lo que México no hacía. Por el déficit constante en las finanzas públicas de la república, el gobierno incumplía en pagar su servicio de deuda, pero incumplía incluso en cosas que implicaban montos mucho menores, como el sueldo de sus empleados, incluido el agente financiero, que se sirvió de esto a la hora de negociar el porcentaje de su comisión por la intermediación. Tan pronto asumió el compromiso de cubrir los presupuestos de las legaciones mexicanas en Europa, Lizardi no paró de solicitar al gobierno mexicano que cumpliera sus compromisos y entregara a sus agentes en México los montos entregados a las legaciones en el viejo continente.

Los hermanos Lizardi comprendieron desde el inicio que su principal activo en la relación establecida con el gobierno mexicano era su nacionalidad. Cuando Miguel Santa María los presentó al ministro de Relaciones en 1836 argumentó ver en ellos "sentimientos verdaderamente patrióticos". Esto serviría para ejercer presión al gobierno mexicano, se que mes tras mes escribirían, vía los ministerios de Relaciones y de Hacienda, solicitando el pago de sus adeudos.

Desde la llegada de Pedro de la Quintana a México, entre diciembre de 1836 y enero de 1837, el agente informó a Londres que no había logrado que se le abonaran ninguna de las letras enviadas contra las legaciones en pago de los suplementos entregados. El encargado de cobrar las letras en México era la casa Sres. Viuda de Echeverría e Hijos, quienes recolectaban los montos de las letras más 1\% de comisión, el que Lizardi solicitaba fuera

${ }^{50}$ Los montos fueron tomados del informe de Alamán, Liquidación general, p. 82, cuadro 10. La cifra que se anota es en números enteros. 
aumentado a $2 \%$. Argumentaban entonces que "por grande que sea el sentimiento y el patriótico deseo con que deseamos evitar a toda costa este resultado que tanto comprometería la dignidad y buen nombre del Supremo Gobierno, no nos sería posible evitarlo, porque los sacrificios tienen un límite del que no se puede pasar aun con la voluntad de continuarlos". ${ }^{51}$

Debido a la falta de pago, Lizardi pidió que se destinara mensualmente una renta fija para su cumplimiento, pues hasta julio de 1837 no habían recibido un solo pago de sus anticipaciones. ${ }^{52}$ Luego de la reunión de agosto de 1837, cuando el negocio estaba a punto de cerrarse, Lizardi informó al gobierno mexicano que necesitaba poderes para ello y de paso solicitó un aumento a $2.5 \%$ de comisión por cada cien acres de terrenos entregados a los tenedores de bonos, así como un 1\% sobre los certificados que expidieran contra las aduanas marítimas. El ministro de Relaciones respondió que, luego de solicitar la opinión del Consejo de Gobierno, éste se manifestó en contra porque el acuerdo alcanzado con los tenedores de bonos en septiembre de 1837 iba en contra del decreto de 12 de abril, razón suficiente para argumentar que Lizardi no había cumplido su misión. ${ }^{53}$

Mientras tanto, en México la casa Viuda de Echeverría e Hijos negoció con el gobierno para que parte de lo que se adeudaba a Lizardi se pagara con los impuestos de las aduanas marítimas de Veracruz y Tampico; sin embargo, el bloqueo francés impidió el cumplimiento del pago. Ante esto Gorostiza escribió a Londres para informar que, en su lugar, se destinarían 3000 pesos de la casa de moneda de Zacatecas, 3000 más de la tesorería del departamento de Guanajuato y 4000 pesos de la administración

${ }^{51}$ AHGE-SRE, 3-11-4709, f. 1. De F. de Lizardi y Cía. al ministro de Relaciones, Londres (15 abr. 1837).

52 AHGE-SRE, 3-11-4709, ff. 8-9. De F. de Lizardi y Cía. al ministro de Relaciones, Londres (28 jun. 1837).

${ }^{53}$ AHGE-SRE, 3-11-4709, ff. 29-30. Del ministro de Hacienda al ministro de Relaciones, México (6 nov. 1837). Alamán, Liquidación general, p. 32. 
general de rentas, además de que "el E.S. presidente me manda les recomiende a UU en nombre de la patria continúen prestando tan importante servicio". 54

Aunque las cosas parecían haberse solucionado, en agosto Almonte le escribió al ministro de Relaciones Exteriores para informarle de un intercambio epistolar que tuvo con Lizardi. A finales de julio F. de Lizardi y Cía. le había comunicado que, debido al bloqueo de los puertos de México por buques franceses, tenía escasez de metálico, por lo que a partir de agosto sólo podrían cubrir la mitad del presupuesto de la representación en Londres, lo mismo que en el resto de Europa. Ante esto Almonte solicitó que se hiciera una excepción en su caso, pues la presencia de un diplomático mexicano en Londres era vital y cortar el presupuesto a la mitad apenas alcanzaría para mantener la legación en pie, pues el envío de correspondencia a México ocupaba casi la mitad del mismo. En caso de que Lizardi se negara, Almonte le informaba que no tenía otra opción que tomar el siguiente paquebote de regreso a México, para lo que le solicitaba recursos. Luego de este intercambio la casa aceptó cubrir los importes, porque consideró que cerrar la representación traería un "descrédito completo de nuestro gobierno [por lo que] puede contar con el presupuesto completo de la legación a su cargo, resignándonos a este mayor desembolso en obsequio de nuestra patria". ${ }^{5}$

El gobierno buscó cubrir los adeudos con los recursos previamente referidos, pero pronto Lizardi volvió a quejarse porque parte de las cantidades recibidas fueron en moneda de cobre,

${ }_{54}$ AHGE-SRE, 3-11-4710, f. 16. Del ministro de Hacienda al ministro de Relaciones, México (3 jul. 1838) [copia de la carta enviada a Lizardi en 25 jun. 1838].

55 AHGE-SRE, 3-11-4710, ff. 62-67. De F. de Lizardi y Cía., a J.N. Almonte, Londres (28 jul. y 4 ago. 1838). De J.N. Almonte a F. de Lizardi y Cía. Londres (1a ago. 1838). De J.N. Almonte al ministro de Relaciones Exteriores, Londres (4 ago. 1838). 
lo que para sus operaciones internacionales era prácticamente inservible. Ante esto, la casa comercial reiteró la solicitud hecha desde un inicio, cuando Quintana presentó el proyecto de conversión de la deuda, y que consistía en que se permitiera a Lizardi emitir bonos en Londres para cubrir su comisión, a lo que se respondió con largas. ${ }^{56}$

La presión de Lizardi se incrementó. Cada que las legaciones necesitaban dinero extra, la casa comercial insistía en que era complicado incluso cubrir los gastos presupuestados, porque seguía sin recibir montos suficientes de México. Así, existen comunicaciones de la legación mexicana en Londres firmadas por Agustín de Iturbide, Máximo Garro, Juan Nepomuceno Almonte y Tomás Murphy, solicitando encarecidamente a los ministros de Relaciones Exteriores y de Hacienda que pagaran a Lizardi.

Pese a que endureció su posición, la firma no dejó de dirigirse al gobierno mexicano con el tono patriótico acostumbrado: "nada hemos reclamado sobre el particular por el estado de penuria y compromiso en que considerábamos a ese gobierno y se nos hizo un deber patriótico como mexicanos el continuar ese servicio en circunstancias tan críticas, y en las que más que nunca podían serle útiles sus empleados en Europa”. No obstante, el siguiente paquete que llegó a Londres no traía noticia de sus pagos, por lo que anunció que dejaría de facilitar los presupuestos a las legaciones europeas a partir del 1을 de enero de $1840 .{ }^{57}$ Nuevamente, el gobierno cedió ante la presión de Lizardi, asignó algunas rentas para cubrir los pagos e informó que consideraría aumentar a $2 \%$ la comisión por la conversión

56 AHGE-SRE, 3-11-4710, ff. 87 y 99. De F. de Lizardi y Cía. al ministro de Relaciones Exteriores, Londres (15 nov. 1838). Del ministro de Relaciones Exteriores a F. de Lizardi y Cía., México (28 dic. 1838).

57 AHGE-SRE, 3-11-4711, ff. 78-79. De F. de Lizardi al ministro de Relaciones Exteriores, Londres (9 y 12 jul. 1839). 
de los bonos de deuda. El 28 de diciembre Lizardi informó a Murphy que había decidido no suspender el pago a las legaciones y continuarlo por tres meses a la espera de que se honrara el compromiso. ${ }^{58} \mathrm{La}$ fecha límite establecida coincidiría con la llegada del primer dividendo, una vez ratificada la conversión en junio del año anterior.

Puesto que Lizardi comenzó a emitir certificados de aduanas, todas las partes se dieron cuenta de la imposibilidad de cumplir con los términos de la conversión mientras se siguieran emitiendo dichas figuras. En Londres la firma sondeó el tema con el comité de tenedores de bonos para luego escribir al gobierno mexicano. De acuerdo con los comentarios que recogió, no quedaba otro medio para regularizar los pagos que capitalizar nuevamente los intereses vencidos entre abril de 1838 y el mismo mes de 1840, o en todo caso asignar un recurso extraordinario para cubrirlos. El presidente del comité le escribió a Murphy con un plan que implicaba la capitalización de dos años de intereses vencidos en bonos al $5 \%$ y que se aumentaran a $20 \%$ los derechos de las aduanas de Veracruz y Tampico para el pago de dividendos. ${ }^{59}$ Lizardi por su parte recomendó al gobierno su propio plan, que se diferenciaba en que los dividendos atrasados se convirtieran en bonos de la nueva conversión, pero éstos se emitirían en dos formas, activos y diferidos. Además, sugería buscar una renta específica para formar un fondo de amortización, algo que no había sido considerado. Al conocerse esto en Londres, el precio de los bonos subiría, lo que ayudaría a lograr un acuerdo rápido. ${ }^{60}$

58 AHGE-SRE, 3-11-4711, f. 119. De F. de Lizardi a Tomás Murphy, Londres (28 dic. 1839).

59 AHGE-SRE, 3-11-4712, ff. 12-14. De G.R. Robinson a Thomas Murphy, Londres (14 abr. 1840).

60 Alamán, Liquidación general, p. 38; Murphy, Memoria sobre la deuda, p. 14. 
Tanto Lizardi como Murphy intercambiaron comunicaciones con miembros del comité para presentar posibles modificaciones. ${ }^{61}$ Se dieron negociaciones por cerca de dos meses, en que sobre todo se discutió la cancelación de la emisión de certificados de aduanas, así como el alcance de las facultades del agente financiero y el encargado de negocios para lograr un arreglo. El comité estaba de acuerdo en detener la emisión de certificados cuando menos hasta octubre, fecha en que se recibiría respuesta del gobierno mexicano relativa a la capitalización de dividendos de dos años y al aumento a $20 \%$ del total de impuestos de aduanas marítimas de Veracruz y Tampico. A su vez, el comité hizo énfasis en que se debería llamar a junta general hasta recibir una respuesta positiva de México. ${ }^{62}$

Se tuvo noticia en Londres hasta siete meses después. La aprobación del Congreso tomó meses, hasta el 28 de agosto de 1841, en que se aprobó una ley cuya copia se remitió a Lizardi, pese a que no se publicó en México. El decreto, sin embargo, únicamente aprobó el aumento a $20 \%$ de ingresos por las aduanas marítimas de Veracruz y Tampico, suponiendo que luego de

61 Alamán, Liquidación general, pp. 38-39; Murphy, Memoria sobre la deu$d a$, pp. 14-15. Debido a que se entablarían nuevas negociaciones con el comité de tenedores de bonos, Murphy escribió al ministro de Relaciones Exteriores para "que las instrucciones que se sirva darme sobre la materia, sean tan claras, precisas y terminantes para sancionar la transacción que se haga con los acreedores, que se evite todo riesgo de hacer lo que después tendrá el gobierno acaso dificultad en ratificar, en el supuesto de que no me separaré ni un ápice de las órdenes de V.E.”. AHGE-SRE, 3-11-4712, ff. 18-20v. De Thomas Murphy al ministro de Relaciones Exteriores, Londres (15 abr. 1840).

${ }^{62}$ AHGE-SRE, 3-11-4712, ff. 33-50. De Thomas Murphy al ministro de Relaciones Exteriores, Londres (15 mayo 1840). De F. de Lizardi y Cía. a G.R. Robinson, Londres (18 abr. 1840). De G.R. Robinson a F. de Lizardi y Cía., Londres (28 abr. 1840). De F. de Lizardi y Cía. a Thomas Murphy, Londres (30 abr. 1840). De Thomas Murphy a F. de Lizardi y Cía., Londres (5 mayo 1840). De F. de Lizardi y Cía. a Thomas Murphy, Londres (15 mayo 1840). De J.D. Powles a F. de Lizardi y Cía., Londres (14 mayo 1840). De J.D. Powles a Thomas Murphy, Londres (14 mayo 1840). 
cubrir el dividendo correspondiente habría un sobrante que se destinaría a satisfacer el pago de dividendos vencidos. ${ }^{63}$

La copia de la ley llegó a Londres hasta el 11 de octubre de 1841, es decir, casi una semana después del vencimiento del dividendo de aquel mes, por lo que los comisionados mexicanos siguieron entregando certificados de aduanas, ante el claro descontento del comité de tenedores de bonos, que recibió el decreto del gobierno mexicano antes que Lizardi. Debido a que toda esta negociación dejó de ser una asunto confidencial, pues se hizo pública en los diarios de Londres, sería imposible llamar a junta general de tenedores de bonos y lograr que se aceptara una rebaja más, pese al anuncio de Lizardi de haber recibido poco más de 55000 pesos para el pago de dividendos, al tiempo que el comité publicó una carta de México donde se afirmaba que, pese a que había una revolución en pie, la separación de montos en las aduanas marítimas no había sido afectada. ${ }^{64}$ No obstante, sería cosa de tiempo que el desorden interno afectara la recaudación, pues la conspiración política fue orquestada por varios comerciantes afectados por el aumento de impuestos, quienes buscaron a líderes militares en varias zonas del país para asegurar el levantamiento. Para octubre Santa Anna ya había sido favorecido como presidente provisional por una junta de representantes, de acuerdo con las Bases de Tacubaya. ${ }^{65}$

A inicios de febrero de 1842 Lizardi logró un acuerdo con el comité y se convocó a reunión general, que tuvo lugar el 11 de febrero. ${ }^{66} \mathrm{La}$ junta fue reportada por los principales diarios de Londres y, de acuerdo con ésta, el gobierno aceptó aumentar a $20 \%$ de lo recaudado en las aduanas marítimas de Veracruz y

63 Dublán y Lozano, Legislación mexicana, IV, p. 29; Alamán, Liquidación general, pp. 40-42; MuRPHY, Memoria sobre la deuda, p. 15.

64 "Money-Market and City Intelligence", The Times (12 oct. y 2 nov. 1841).

${ }^{65}$ Vázquez, Dos décadas, pp. 84-89; Costeloe, "The Triangular Revolt".

${ }^{66}$ AHGE-SRE, 3-11-4714, ff. 16-18. De Thomas Murphy al ministro de Relaciones Exteriores y Gobernación (1 feb. 1842). 
Tampico para el pago de dividendos, además de destinar $5 \%$ de los derechos recaudados en las aduanas del Pacífico para crear un fondo de amortización. A cambio, los tenedores de bonos aceptaron que los ocho dividendos atrasados entre 1838 y 1841 no se capitalizaran, sino que se creara una figura nueva llamada debentura, que se pagaría con el sobrante del $20 \%$ de impuestos aduanales, una vez cubierto el dividendo corriente. Lizardi logró también que el monto de los ocho dividendos referidos fuera reducido a 50\%. En la junta se mencionó que el plan presentado por Lizardi no tenía la venia del nuevo gobierno, pero el agente zanjó el problema al presentar una comunicación enviada por Antonio López de Santa Anna, con fecha 12 de diciembre de 1841, donde se aprobaba el plan presentado. ${ }^{67}$

El 15 de febrero de 1842 Murphy informó a México del logro obtenido, aunque se quejó de haber sido excluido de la negociación final. ${ }^{68}$ La parte en que sí contribuyó Murphy fue en la solicitud a Baring Brothers para que entregara los montos que tenía en su poder hasta antes del cambio en la agencia financiera, lo que serviría para completar el pago del dividendo de abril de 1842. La firma británica entregó 26332 libras al diplomático mexicano con lo que, después de años de atrasos, el país finalmente pagó los dos dividendos de 1842 completos. Los bonos activos llegaron a cotizar a un máximo de $42.5 \%$, algo no visto en más de una década. ${ }^{69}$

67 AHGE-SRE, 3-11-4714, ff. 19-22. "Convenio celebrado entre los Ss. Lizardi y Cía., a nombre del Gobierno mexicano y los tenedores de bonos Hispanoamericanos" (12 feb. 1842). Murphy, Memoria sobre la deuda, pp. 152-155, núm. 5, contiene una copia del convenio. "Money-Market and City Intelligence”, The Times (9 y 12 feb. 1842). No fue posible localizar alguna copia de la comunicación de Santa Anna.

${ }_{68}$ AHGE-SRE, 3-11-4714, ff. 28-31v. De Thomas Murphy al ministro de Relaciones Exteriores y Gobernación (15 feb. 1842).

${ }^{69}$ AHGE-SRE, 3-11-4714, ff. 33 y 35. De Thomas Murphy a Baring hermanos y Cía., Londres (19 feb. 1842). De Thomas Murphy al ministro de 
A la muerte de Francisco de Lizardi en marzo de 1842, su hermano Manuel Julián se puso al frente de la firma. El cambio en la jefatura de la casa comercial modificó la relación con el gobierno mexicano. Las solicitudes para el pago de su comisión $\mathrm{y}$ de los abonos hechos a las legaciones en Europa subieron de tono. En septiembre, por ejemplo, el gobierno instruyó a Murphy informar al agente financiero que no se podrían cubrir sus adeudos. ${ }^{70}$ Ante esto, Manuel Lizardi endureció su postura y le informó que a partir de octubre de 1842 se entregarían recursos a las legaciones luego de firmar letras con un aumento de $5 \%$ e interés de $1 \%$ mensual.

La presión ejercida finalmente tuvo resultados vía el ministro de Hacienda, Ignacio Trigueros, quien envió tres comunicaciones a Londres. La primera era la ratificación por parte del gobierno de Santa Anna del convenio celebrado en febrero de $1842,{ }^{71}$ en tanto las otras dos instruían a Lizardi para que emitiera la cantidad de bonos suficiente para cubrir todos sus adeudos, así como el aumento de $5 \%$ de su comisión como recompensa al servicio prestado a la nación. ${ }^{72}$

Murphy no tuvo conocimiento de las cartas sino hasta casi un año después, de mano de Manuel Lizardi, quien le entregó una copia. Pero desde principios de noviembre de 1842 corría el rumor en los círculos financieros de Londres de que la suma de bonos en circulación era superior a la totalidad de los bonos que se había acordado convertir. James van Sommer, secretario del comité de la bolsa de Londres, entabló una serie

Relaciones Exteriores y Gobernación (1ำ mar. 1842). Costeloe, Deuda externa, pp. 50-51 y 71, cuadros I.1, I.2 y I.5.

70 AHGE-SRE, 3-11-4714, ff. 80-81. Del ministro de Hacienda al ministro de Relaciones Exteriores y Gobernación, México (28 jul. 1842). De Thomas Murphy a F. Lizardi y Cía., Londres (sep. 1842).

${ }^{71}$ Dublán y Lozano, Legislación mexicana, IV, pp. 281-283.

72 Murphy, Memoria sobre la deuda, pp. 28-29. Lizardi se encargó de hacer llegar las cartas a Murphy. 
de comunicaciones con F. de Lizardi y Cía., en que solicitó noticia de la suma y números respectivos de cada serie de bonos emitidos. Lizardi se negó con el argumento de que esa información sólo la podía entregar previa autorización del gobierno mexicano. El presidente del comité de tenedores de bonos hispanoamericanos también le escribió a Lizardi para solicitar que, de acuerdo con el convenio establecido entre ambas partes, la emisión de bonos del fondo nacional consolidado debía limitarse "al solo y determinado objeto de convertir en su totalidad la deuda extranjera", que de acuerdo con el comité equivalía a 9247937 libras. ${ }^{73}$

Finalmente, el 25 de noviembre de 1842 Lizardi entregó noticia al comité de tenedores de bonos sobre la emisión, que entre activos y diferidos sumaba 10800000 libras, a lo que añadían que "el importe de nuestra comisión está comprendido en la antedicha creación de bonos". De esta forma, de acuerdo con los cálculos del comité de la bolsa, Lizardi habrían emitido poco más de 1000000 y medio de libras extra en bonos de deuda mexicana. La historiografía ha dado en llamar a esta acción la "emisión clandestina de bonos activos", porque cuando detectaron la acción de Lizardi ya había en circulación 630531 libras y todavía tenían en su posesión 145500 libras más, sin contar la emisión extraordinaria de bonos diferidos.

Luego de una serie de negociaciones, el gobierno mexicano había conseguido reprogramar su servicio de deuda. Se acordó la conversión de los bonos viejos de 5 y $6 \%$ en un solo fondo consolidado de $5 \%$, además de la emisión de nuevas figuras como los bonos diferidos, los certificados de aduanas marítimas y las debenturas. El asunto se había vuelto más complejo, pero existía

\footnotetext{
73 Todas las comunicaciones fueron recopiladas por el comité de la bolsa de Londres y publicadas en un breve folleto titulado "Conversion of Mexican Bonds. Report of the Committee of Stock Exchange”. AHGE-SRE, 4-114714, ff. 130-131. También existen copias de las comunicaciones en MurPHY, Memoria sobre la deuda, pp. 17-25.
} 
un acuerdo entre ambas partes. En 1842 México pudo restablecer el pago de su servicio de deuda y sus bonos activos cotizaban en el mercado a precios no vistos en más de una década; sin embargo, F. de Lizardi y Cía. había cobrado sus servicios con una acción que, si bien contaba con la aprobación del gobierno de Santa Anna, iba en contra de las leyes que habían dado forma a todo el proceso y volvía a lastimar la maltrecha reputación crediticia del país. Los bonos mexicanos cayeron 10\% al cierre del año.

\section{CONCLUSIONES}

El arreglo establecido con los tenedores de bonos en 1831, por el que una parte de los bonos de deuda comenzarían a generar intereses en 1836, fue el detonante para un tema que había sido abandonado por la política nacional. Cuando Baring Brothers recibió una respuesta ambigua sobre cómo proceder, renunció a representar un país al que parecía no importarle su reputación financiera. Dentro, México se debatía entre cambiar de sistema de gobierno, pues se culpaba al federalismo de la persistente inestabilidad política y económica.

El episodio de diplomacia financiera aquí analizado no puede concebirse como originado de manera consciente por el gobierno de México, pues el país se encontraba en el tránsito hacia el centralismo. La llegada de la fecha límite del acuerdo de 1831, junto con la renuncia del agente financiero, presentaron la coyuntura que fue aprovechada por la casa F. de Lizardi y Cía.

Al convertirse en el agente financiero del gobierno mexicano, Lizardi presentó un plan para la reorganización de la deuda que parecía muy ingenioso. Éste implicaba la unificación de los dos créditos contratados en 1824 y 1825 en un solo fondo consolidado, del que se emitiría la mitad en bonos activos y la otra mitad podría cambiarse por tierras en el norte del país. El plan además establecía 5\% de interés, por lo que reducía el pago del 
dividendo a la mitad y a una sola tasa. En términos de política exterior, concebía que la entrega de tierras en Texas permitiría crear un bloque de apoyo británico para combatir el separatismo texano y el inminente expansionismo estadounidense.

Una serie de acciones aquí analizadas impidieron que el plan tuviera el éxito esperado. En primer lugar, la falta de concordancia entre el plan y las expectativas de los tenedores de bonos. Al parecer, tanto Lizardi como los miembros del gobierno mexicano consideraban que los tenedores de bonos aceptarían el proyecto sin mover una coma, lo que era bastante improbable. En segundo lugar, no se consideró que la tardanza en las comunicaciones impediría el éxito del proyecto. Puesto que sufrió modificaciones, hubiera sido deseable que los representantes del gobierno mexicano tuvieran facultades suficientes para realizarlas, sin que esto representara un mayor obstáculo a la búsqueda de acuerdos. Esto generó que el plan inicial y sus varias modificaciones tuvieran que pasar por la ruta larga de la aprobación en comisiones en las dos cámaras del Legislativo, la promulgación del decreto, el envío de instrucciones al ministro plenipotenciario o encargado de negocios en Londres, así como al agente financiero, quienes presentarían las modificaciones al comité de tenedores de bonos, y si éste lo consideraba conveniente lo presentaría a los tenedores de bonos en una junta general. En tercer lugar, la figura del agente financiero estaba en estos momentos desligada de los miembros del incipiente servicio diplomático.

Durante la primera década de vida independiente el gobierno mexicano consideró a los agentes financieros como ajenos al servicio diplomático, pues juzgaba que esa figura debía ser ocupada por alguien que estuviera inserto en el núcleo del sistema financiero internacional, es decir, que residiera en Londres y se dedicara a las finanzas. La comisión que se dio a Francisco de Borja Migoni para contratar un préstamo en Londres es prueba de ello. Posteriormente, se contrató a Barclay como agente financiero, para que a su quiebra Baring Brothers y Compañía 
asumiera el encargo. Ante la falta de pago de dividendos y el envío de instrucciones sobre la manera de proceder, Baring renunció y dio paso a la llegada de F. de Lizardi y Cía., cuyos principales socios eran mexicanos. En ese sentido, los hermanos Lizardi cumplían con el expertise para hacerse cargo del puesto, además de ser mexicanos.

Regresando al modelo de Gould y Fernández expuesto al inicio, el gobierno mexicano consideró que por primera vez el agente financiero fungiría como "representante" de los intereses nacionales, en el sentido de una filiación compartida, por lo que coordinaría y negociaría con una parte externa, en este caso los tenedores de bonos. Santa María y varios de los diplomáticos mexicanos apelaron constantemente al patriotismo de Lizardi cuando aceptó cubrir los presupuestos de las legaciones en Europa además de velar por la reputación crediticia del país en Londres. Más allá de si aquellos que lo enunciaron realmente creían en su patriotismo, así es como se catalogó a los Lizardi.

Por su parte, F. de Lizardi y Compañía comprendió desde el inicio que el hecho de haber nacido en Veracruz y tener negocios en México era un activo importante para hacerse cargo de la agencia financiera. Lizardi también apeló a ese discurso a conveniencia; sin embargo, cuando tenía que apretar al gobierno mexicano y sus representantes en Londres, el interés particular prevalecía por encima de cualquier sentido de identidad. Al final de cuentas, siguiendo a Salvucci y Salvucci, los hermanos Lizardi "podían ser patriotas en el momento fluido y cambiante de la época, pero ante todo eran banqueros".$^{74}$ Por tanto, en el esquema de intermediación propuesto, los Lizardi no actuaron en este proceso como "representantes" del gobierno mexicano, sino más bien como "enlace". Es decir, como un intermediario cuya filiación es externa, por lo que coordina el intercambio de

${ }_{74}$ Salvucci y Salvucci, “The Lizardi Brothers”, p. 762. 
intereses entre dos grupos distintos, en este caso el gobierno mexicano y los tenedores de bonos.

\section{Gráfica 1}

INTERMEDIACIÓN EN LA CONVERSIÓN DE LA DEUDA EXTERNA MEXICANA, 1836-1842

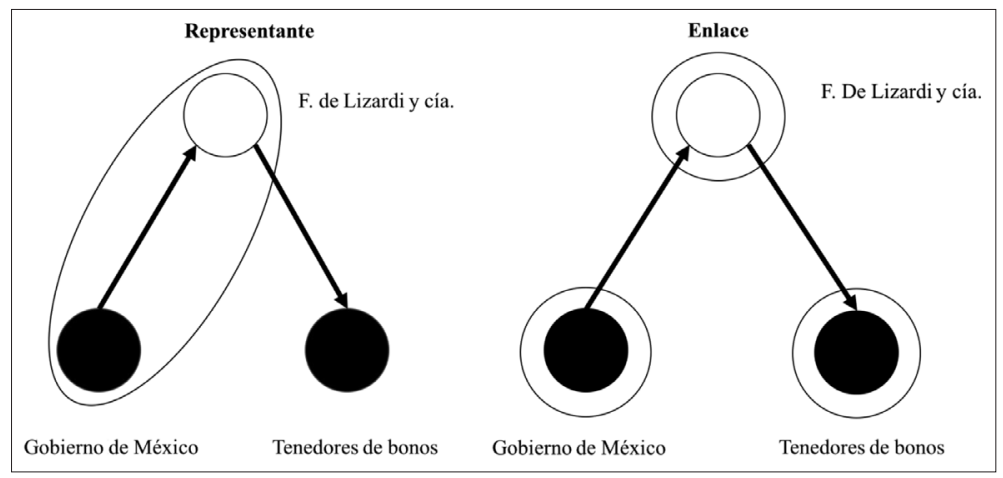

Fuente: elaboración propia, a partir de Gould y Fernandez, "Structures of Mediation".

La gráfica 1 ilustra el proceso de intermediación en el episodio de diplomacia financiera aquí analizado. El círculo de la parte superior es el intermediario, en tanto los dos círculos de abajo representan a los actores del intercambio y las flechas señalan el flujo del interés por establecer el intercambio. La elipse de la relación de intermediación de la izquierda refleja la percepción o expectativa del gobierno mexicano, en la que se representa al intermediario como alguien que pertenece a una de las partes del intercambio, lo que aquí refiere al origen mexicano de los Lizardi. En la segunda parte de la gráfica se ve que todas las partes tienen filiaciones independientes una de la otra, por lo que cada una buscará su propio beneficio. La parte derecha ilustra la percepción o expectativa de los Lizardi en la operación. 
La diplomacia financiera del gobierno mexicano no tuvo el éxito esperado debido a la estructura misma del incipiente servicio diplomático. Aunque en teoría el agente financiero debía representar las directrices de los ministerios de Hacienda y Relaciones Exteriores del gobierno mexicano, en la realidad los intereses públicos tropezaron en todo el proceso de negociación con los intereses privados de Lizardi.

Finalmente, no debe perderse de vista que, independientemente de las acciones e intereses de los agentes financieros de México en Londres, el principal reto del gobierno mexicano para cumplir con el servicio de deuda era el déficit constante de las finanzas públicas, tanto en el federalismo como en el centralismo. Una serie de reformas fiscales que implicaron la creación de varios impuestos directos logró mejorar la recaudación, pero el déficit continuó durante décadas, lo mismo que el impago del servicio de deuda. Esto dio pie a otros episodios de diplomacia financiera que investigaciones futuras deberán abordar para contribuir a una mejor comprensión de los procesos de negociación internacional en materia financiera.

\section{SIGLAS Y REFERENCIAS}

AHGE-SRE Archivo Histórico Genaro Estrada de la Secretaría de Relaciones Exteriores, México.

Aboites Aguilar, Luis y Luis Jáuregui (coords.), Penuria sin fin. Historia de los impuestos en México, siglos XVIII-XX, México, Instituto Mora, 2005.

Aggarwal, Vinod K., Debt Games. Strategic Interaction in International Debt Rescheduling, Cambridge, Cambridge University Press, 1996.

Alamán, Lucas, Liquidación general de la deuda esterior de la República Mexicana hasta fin de diciembre de 1841, México, Ignacio Cumplido, 1845.

Andrews, Catherine, Entre la espada y la Constitución. El general Anastasio Bustamante, 1780-1853, Ciudad Victoria, Universidad Autónoma de Tamaulipas, H. Congreso del Estado de Tamaulipas, LX Legislatura, 2008. 
Austin, Peter E., Baring Brothers and the Birth of Modern Finance, Londres, Pickering \& Chatto, 2007.

Bayne, Nicholas y Stephen Woolcock, "What is Economic Diplomacy?", en Bayne y WoOlcock (eds.), 2007, pp. 1-20.

Bayne, Nicholas y Stephen Woolcock (eds.), The New Economic Diplomacy: Decision-Making and Negotiation in International Economic Relations, Ashgate, Routledge, 2007.

Bayne, Nicholas, "Financial Diplomacy and the Credit Crunch: The Rise of Central Banks", en Journal of International Affairs, 62: 1 (2008), pp. 1-16.

Bazant, Jan, Historia de la deuda externa de México, 1823-1946, México, El Colegio de México, 1995.

Colección de leyes y disposiciones relativas al crédito público desde el año 1821 primero de la independencia, que se forma y publica en cumplimiento de orden de la secretaría de Estado y del despacho de Hacienda y Crédito Público, 2 tomos, México, Imprenta Agrícola-Comercial, 1883.

Costeloe, Michael P., "The Triangular Revolt in Mexico and the Fall of Anastasio Bustamante, August-October, 1841", en Journal of Latin American Studies, 20: 2 (1998), pp. 337-360.

Costeloe, Michael P., Deuda externa de México. Bonos y tenedores de bonos, 1824-1888, México, Fondo de Cultura Económica, 2007.

Costeloe, Michael P., La primera república federal de México (1824-1835). Un estudio de los partidos políticos en el México independiente, México, Fondo de Cultura Económica, 1975.

Costeloe, Michael P., La República central en México, 1835-1846. "Hombres de bien” en la época de Santa Anna, México, Fondo de Cultura Económica, 2000.

Dawson, Frank Griffith, The First Latin American Debt Crisis. The City of London and the 1822-25 Loan Bubble, New Haven y Londres, Yale University Press, 1990.

Dublán, Manuel y José María Lozano, Legislación mexicana, o colección completa de las disposiciones legislativas desde la independencia de la República, tomos 3 y 4, México, Imprenta a cargo de Dublán y Lozano hijos, 1876. 
Ferguson, Niall, The House of Rothschild. Money's Prophets, 1798-1848, Nueva York, Penguin Books, 1999.

Flandreau, Marc y Juan H. Flores, "Bonds and Brands: Foundations of Sovereign Debt Markets, 1820-1830", en The Journal of Economic History, 69: 3 (sep. 2009), pp. 646-684.

Gould, Roger V. y Roberto M. Fernandez, "Structures of Mediation: A Formal Approach to Brokerage in Transaction Networks", en Sociological Methodology, 19 (1989), pp. 89-126.

Hernández Jaimes, Jesús, La formación de la Hacienda pública mexicana $y$ las tensiones centro-periferias, 1821-1835, México, El Colegio de México, Instituto Mora, Universidad Nacional Autónoma de México, 2013.

Liehr, Reinhard, "La deuda exterior de México y los merchant bankers británicos, 1821-1860”, en LudLOw y MARICHAL (coords.), 1998, pp. 25-52.

Ludlow, Leonor y Carlos Marichal (coords.), Un siglo de deuda pública en México, México, Instituto Mora, El Colegio de Michoacán, El Colegio de México, Universidad Nacional Autónoma de México, 1998.

Marichal, Carlos, Historia de la deuda externa de América Latina, México, Alianza Editorial Mexicana, 1988.

Murphy, Tomás, Memoria sobre la deuda esterior de la República Mexicana desde su creación hasta fines de 1847, París, Ad. Blondeau, 1848.

Okano-Heijmans, Maaike, "Conceptualizing Economic Diplomacy: The Crossroads of International Relations, Economics, IPE and Diplomatic Studies", en The Hague Journal of Diplomacy, 6: 1-2 (2011), pp. 7-36.

Rodríguez O., Jaime E., “Los primeros empréstitos mexicanos, 1824-1825”, en Ludlow y Marichal (coords.), 1998, pp. 53-80.

Rodríguez O., Jaime E. (ed.), Patterns of Contention in Mexican History, Wilmington, SR Books, 1992.

Rodríguez O., Jaime E., El nacimiento de Hispanoamérica. Vicente Rocafuerte y el hispanoamericanismo, 1808-1832, México, Fondo de Cultura Económica, 1980. 
Salvucci, Richard J. y Linda K. Salvucci, “The Lizardi Brothers: A Mexican Family Business and the Expansion of New Orleans, 1825-1846", en The Journal of Southern History, LXXXII: 4 (nov. 2016), pp. 759-788.

Salvucci, Richard J., Politics, Markets and Mexico's "London Debt," 18231887, Nueva York, Cambridge University Press, 2009.

SÁnchez Santiró, Ernest, "El peso de la fiscalidad sobre la economía mexicana, 1790-1910”, en Historia Mexicana, LxI: 1 (241) (jul.-sep. 2011), pp. 107-162.

SÁnChez SANTiró, Ernest, Las alcabalas mexicanas (1821-1857). Los dilemas en la construcción de la Hacienda nacional, México, Instituto Mora, 2009.

Serrano Ortega, José Antonio, Igualdad, uniformidad, proporcionalidad. Contribuciones directas y reformas fiscales en México, 1810-1846, México, Instituto Mora, El Colegio de Michoacán, 2007.

Sicotte, Richard y Catalina Vizcarra, "War and Foreign Debt Settlement in Early Republican Spanish America”, en Revista de Historia Económica, 27: 2 (ene. 2009), pp. 247-289.

Soto, Miguel, “Texas y la federación mexicana”, en Vázquez y Serrano ORTEGA (coords.), 2012, pp. 575-594.

Tenenbaum, Barbara A., The Politics of Penury. Debt and Taxes in Mexico, 1821-1856, Albuquerque, University of New Mexico Press, 1986.

Tomz, Michael, Reputation and International Cooperation: Sovereign Debt across Three Centuries, Princeton, Princeton University Press, 2007.

Torres Medina, Javier, Centralismo y reorganización. La Hacienda pública y la administración durante la primera república central de México, 1835-1842, México, Instituto Mora, 2013.

VÁzquez, Josefina Zoraida, "Los pronunciamientos de 1832: aspirantismo político e ideología”, en RodríGuez O. (ed.), 1992, pp. 163-186.

VÁzquez, Josefina Zoraida, Dos décadas de desilusiones. En busca de una fórmula adecuada de gobierno (1832-1851), México, El Colegio de México, Instituto Mora, 2009. 
VÁzquez, Josefina Zoraida, México, Gran Bretaña y otros países (1821-1846), México, El Colegio de México, 2010 (México y el mundo. Historia de sus Relaciones Exteriores, tomo II).

VÁzquez, Josefina Zoraida y José Antonio Serrano Ortega (coords.), Práctica y fracaso del primer federalismo mexicano (1824-1835), México, El Colegio de México, 2012.

Zavala, Lorenzo de, Razón de los préstamos que ha negociado el Supremo Gobierno de la Federación, en virtud de la autorización concedida por los decretos del Congreso General de 21 de noviembre y 24 de diciembre del año de 1827, 3 de octubre y 20 de noviembre de 1828, que se publica con autorización del Ecsmo. Sr. Ministro de Hacienda, ciudadano Lorenzo de Zavala, México, Imprenta del Correo, 1829.

Ziegler, Philip, The Sixth Great Power. A History of One of the Greatest of Gall Banking Families, the House of Barings, 1762-1929, Nueva York, Alfred A. Knopf, 1988. 